\title{
Cost-effectiveness of insulin analogs from the perspective of the Brazilian public health system
}

\author{
Maurílio de Souza Cazarim ${ }^{1 *}$, João Paulo Vilela Rodrigues ${ }^{1}$, Estael Luzia Coelho da \\ Cruz-Cazarim ${ }^{1}$, Lorena Rocha Ayres², Leonardo Régis Leira Pereira ${ }^{1}$
}

\begin{abstract}
${ }^{I}$ Department of Pharmaceutical Sciences, Pharmaceutical Services and Clinical Pharmacy Research Center (CPAFF), School of Pharmaceutical Sciences of Ribeirão Preto, University of São Paulo, Ribeirão Preto, São Paulo, Brazil, ${ }^{2}$ Department of Pharmaceutical Sciences of Federal University of Espirito Santo, Espirito Santo, Brazil
\end{abstract}

\begin{abstract}
Human insulin is provided by the Brazilian Public Health System (BPHS) for the treatment of diabetes, however, legal proceedings to acquire insulin analogs have burdened the BPHS health system. The aim of this study was to perform a cost-effectiveness analysis to compare insulin analogs and human insulins. This is a pharmacoeconomic study of cost-effectiveness. The direct medical cost related to insulin extracted from the Ministry of Health drug price list was considered. The clinical results, i.e. reduction in glycated hemoglobin $(\mathrm{HbA} 1 \mathrm{c})$, were extracted by meta-analysis. Different scenarios were structure to measure the uncertainties regarding the costs and reduction in HbAlc. Decision tree was developed for sensitivity of Incremental Cost Effectiveness Ratio (ICER). A total of fifteen scenarios were structured. Given the best-case scenario for the insulin analogs, the insulins aspart, lispro, glargine and detemir showed an ICER of $\mathrm{R} \$ 1,768.59 ; \mathrm{R} \$ 3,308.54$; $\mathrm{R} \$ 11,718.75$ and $\mathrm{R} \$ 2,685.22$, respectively. In all scenarios in which the minimum effectiveness was proposed, lispro, glargine and detemir were dominant strategies. Sensitivity analysis showed that the aspart had R \$ 3,066.98 [95 \% CI: 2339.22; 4418.53] and detemir had R \$ 6,163.97 [95\% CI: 3919.29; 11401.57] for incremental costs. We concluded there was evidence that the insulin aspart is the most cost-effective.
\end{abstract}

Keywords: Diabetes Mellitus/treatment/cost-effectiveness/evaluation. Prolonged Action Insulin. Short Action Insulin. Brazilian Public Health System.

\section{INTRODUCTION}

Diabetes Mellitus (DM) is a group of chronic metabolic disorders that cause hyperglycemia. If not controlled, DM may trigger vascular complications and impair the function of organs such as the kidneys, brain and heart (ADA, 2016; SBD, 2016; WHO, 2016a). Approximately 415 million people worldwide have DM, $75 \%$ from which live in low- and middle-income countries (IDF, 2016). In Brazil, the prevalence is 8.1\% (WHO, 2016b).

The annual direct costs to the Brazilian Public Health System (BPHS) with DM management reaches 14.8 billion Reais, which represents outpatient spending of R $8,010.00 /$ patient/year (SDB, 2016). This amount

\footnotetext{
*Correspondence: M. S. Cazarim. Centro de Pesquisa em Assistência Farmacêutica e Farmácia Clínica (CPAFF), Faculdade de Ciências Farmacêuticas de Ribeirão Preto, Universidade de São Paulo. Av. Café, s/no , Sala 23, bloco S, 14040-903, Ribeirão Preto - SP, Brasil. Phone: +55 16 3315-4236. E-mail: maurilio.jf@gmail.com
}

includes direct costs related to examinations, medicines and consultations, non-medical direct costs, such as transportation and absenteeism and indirect health care costs, such as those generated by the complications of uncontrolled DM. The treatment effectiveness results in sustained reduction in glycosylated haemoglobin (HbA1c) and cost savings associated to complications and to indirect costs which are the highest costs that burden the BPHS (Rascati, 2010; Do Livramento, Saleh, 2011; Wagner et al., 2001; Obreli-Neto et al., 2015; SDB, 2016).

DM type 1 (DMT1) is usually an autoimmune disorder that results in absolute insulin deficiency. DM type 2 (DMT2) is characterized by the resistance of tissues to the insulin and/or the relative deficiency of insulin. People with DMT1 are insulin-dependent and insulinization is a therapeutic option for DMT2. (ADA, 2016; SBD, 2016). Therapies with human Neutral Protamine Hagedorn (NPH) insulin, Regular (R) insulin and insulin analogs foster discussion about the DM treatment effectiveness 
and involved costs. NPH, a slow-acting insulin, has unfavorable characteristics such as its erratic absorption, causing unpredictable glycemic variations. $\mathrm{R}$ insulin has faster action and is used to control postprandial glycemia, but it presents relatively slow absorption considering its indication. This absorption and the irregular feeding of some patients can result in hypoglycemia and therapeutic failures (SBD, 2011).

Human NPH and R insulin are provided by the BPHS. However, access to human insulin analogs generally occurs through lawsuits (Do Livramento, Saleh, 2011; Figueiredo, Osorio-de-Castro, Pepe, 2013). These unforeseen expenses in the health budget with higher cost medicines burden the BPHS and this increase of expenses to the BPHS has been associated with arbitrary decisions related to provision of the insulin analogs. They have been available through judicial processes in different regions and municipalities of Brazil. The number of lawsuits involving lispro and glargine insulins is twice the number of lawsuits to require other insulin analogs (Lima et al., 2015). Decision-making for health care should be a rational process which does not result in excessive and unnecessary health care costs because this can compromise the system equity and the access to health (Shafie et al., 2016). The decision to provide or to incorporate to BPHS for any insulin analog should be supported by economic analysis and clinical evidence (Brasil, 2014).

In this context, the knowledge about cost-effectiveness of insulin analogs can subsidize health planning and possible incorporation of insulin analogs into the BPHS. The aim of this study was to perform a cost-effectiveness analysis to compare insulin analogs and human insulins.

\section{METHODS}

This is a pharmacoeconomic study of costeffectiveness to perspectives of BPHS. This study was developed based on data from the literature concerning the treatment of DM with insulin therapy. The cost data refer to the month of June 2016 and were recorded in monetary values in Brazilian currency, the Real. The calculation referred to the cost per patient/year.

For this study the direct medical costs of insulin treatment were ranked. The therapeutic regimen for each type of insulin was measured in accordance with the dose described as an International Unit (IU) per kg of the patient, considering for the calculation of the annual cost, 360 days of a year and body weight of $70 \mathrm{~kg}$, being the mean of the normal distribution for the Brazilian population, according to the Brazilian Institute of Geography and Statistics (Brasil, 2016). Thus, the cost per IU of the drug was multiplied by the mean daily dose in IU recommended for each type of insulin, and calculated per patient/year. The mean dose values assigned to each type of insulin were extracted from the studies used in the meta-analysis by Sanches et al. (2013) (Anderson Jr et al., 1997; Home, 2000; Hermansen et al., 2004; Heller, Koenen, Bode, 2009).

Data related to the reduction of $\mathrm{HbA} 1 \mathrm{c}$ were used to compare treatment with human insulin and treatment with insulin analogs, being obtained from the meta-analysis by Sanches et al. (2013). The meta-analysis examined sixteen studies, totaling 5,733 patients using rapid-acting insulin analogs (glulisine, arpart, lispro) and 4,771 patients using long-acting insulin analogs (glargine and detemir). The mean age was 39.2 years and all patients were receiving diabetes treatment with insulin only. Glulisine was excluded from this study because it was not analyzed in the meta-analysis, being as it was found only in a clinical trial that analyzed glulisine vs. insulin R. The meta-analysis considered the significance level of $5 \%$ and the figures were interpreted for $95 \%$ confidence interval (Sanches et al., 2013).

The costs were extracted from the Market of Regulation of the Market of Medicines (CMED). It was considered the price of the sale of medicine to the government and the tax rate of $18 \%$, linked to most Brazilian states. The values of each insulin existing in the table were considered: NPH INSUNORM N (ASPEN PHARMA) 100 IU mL, 10 mL injectable suspension; Regular INSUNORM R (ASPEN PHARMA) $100 \mathrm{IU} / \mathrm{mL}, 10 \mathrm{~mL}$ injectable solution; NOVORAPID aspart (NOVO NORDISK) 100 $\mathrm{IU} / \mathrm{mL}, 10 \mathrm{~mL}$ injectable solution; lispro HUMALOG (ELI LILLY) $100 \mathrm{IU} / \mathrm{mL}, 10 \mathrm{~mL}$ injectable solution; detemir LEVEMIR (NOVO NORDISK) $100 \mathrm{IU} / \mathrm{mL}, 3 \mathrm{~mL}$ injectable solution; and glargine VELUXUS (MEDLEY) $100 \mathrm{IU} / \mathrm{mL}, 3 \mathrm{~mL}$ injectable solution (ANVISA, 2016).

\section{Calculating cost-effectiveness}

For cost-effectiveness analysis the Incremental Cost Effectiveness Ratio (ICER) was calculated, the calculation of which is the ratio of the cost variation by variation of the effectiveness, designated by the expression (Rascati, 2010):

$\mathrm{ICER}=\frac{(\text { cost of human insulin }- \text { cost of insulin analog) }}{\text { (reduciton of HbAlc by human insulin }- \text { reduction of HbAlc by insulin analog) }}$

The ICER refers to the extra cost with the insulin analog in order to obtain an improvement in the outcome, the reduction in $\mathrm{HbA} 1 \mathrm{c}$. Thus, it can be understood that when there is no higher cost and there is an improvement of the outcome, the option becomes dominant in the scenario of the analysis, and when there is a higher cost and worsening outcome, the option becomes dominated in the respective scenario of analysis. 


\section{Simulation of uncertainties}

Different scenarios were structured to measure the possibilities of variation of costs and reduction in $\mathrm{HbAlc}$ achieved by each type of insulin (Drummond et al., 2005). The calculation of the ICER for variations in cost was performed for the mean, minimum, and maximum values, which relate to the cost difference between the mean, minimum, and maximum values of insulin, respectively. The cost was also varied for the largest possible difference and smallest possible difference obtained by the difference between the lowest cost of human insulin and the highest cost of insulin analog, and between the highest cost of human insulin and the lowest cost of insulin analog, respectively. To compose the scenarios of different possibilities for insulin cost-effectiveness, the variation in costs was combined with variation of effectiveness, whether mean, minimum and maximum, for the reduction of HbA1c. The cost-effectiveness threshold was measured by the amount of three times the GDP per capita for the year 2015 as recommended by the Brazilian Network of Technology Assessment in Health (Brasil, 2014).

\section{Sensitivity analysis}

Sensitivity analysis was performed in order to support decision-making regarding the analysis of ICER variation of each type of insulin analog (Drummond et al., 2005; Rascati, 2010). For this, a decision tree was drawn which through the confidence interval for the reduction of $\mathrm{HbA} 1 \mathrm{c}$ demonstrated the sensitivity of the analysis, given the variation of effectiveness. In this model of analysis, calculated probabilities were considered with a 95\% confidence interval for the minimum and maximum variation in $\mathrm{HbAlc}$, and for the variation in the minimum and maximum cost of each insulin types. For construction of the decision tree the first node of the tree was defined as being the decision node between two representatives of each insulin-class of fast and long-acting action. This node branched into a probability node related to the probability of minimum and maximum effectiveness of each insulin. Each probability node branched into a terminal node with the probability of variation in maximum and minimum cost for each insulin.

The probabilities were obtained within the confidence interval itself. For the probability of the minimum value the ratio between the minimum value and the sum of the values within the interval was calculated, and the probability of the maximum value followed the expression: (1 - probability of minimum value). Thus, the smaller the amplitude between the maximum and minimum values of the confidence interval, the lower the probability for values to differ from the mean, both for effectiveness and cost, i.e. the result is more consistent with the mean which was used for calculating the cost-effectiveness ratio.

\section{RESULTS}

When insulin analogs were compared with human insulin, fast acing $\mathrm{R}$ and long-acting NPH, the insulin analogs that presented greater effectiveness were aspart and detemir, which showed a further reduction of $-0.13 \%$ [95\% CI: $-0.17 ;-0.09$ ] and $-0.11 \%$ [95\% CI: $-0.32 ; 0.11]$ in mean $\mathrm{HbA1c}$, respectively. It should be highlighted that among the insulin analogs, aspart and detemir were the options that presented the lowest mean cost of treatment per patient/year, R\$ 665.34 [95\% CI: 591.41; 739.26] and R\$ 1,752.66 [95\% CI: 1448.86; 2056.45], respectively. It was observed that the highest cost that aspart could present was still lower than the lowest cost of the analog option analyzed, namely lispro. A similar situation was not verified for the long-acting insulin analogs (Table I).

TABLE I - Effectiveness of insulin analogs in reducing HbA1c compared to human insulins and the annual cost for treatment

\begin{tabular}{|c|c|c|c|c|c|}
\hline \multirow{2}{*}{ Insulins } & \multirow{2}{*}{$\begin{array}{c}\text { Reduction in } \\
\text { HbA1c (CI } 95 \%)\end{array}$} & \multirow{2}{*}{$\begin{array}{l}\text { Daily dose IU/Kg } \\
\text { (CI } 95 \%)\end{array}$} & \multicolumn{3}{|c|}{ R\$ Cost of treatment patient/year } \\
\hline & & & Minimum & Mean & Maximum \\
\hline \multicolumn{6}{|l|}{ Fast acting } \\
\hline REGULAR & Reference & $0.68(0.62 ; 0.73)$ & 500.75 & 549.20 & 589.59 \\
\hline Aspart & $-0.13(-0.17 ;-0.09)$ & $0.36(0.32 ; 0.40)$ & 591.41 & 665.34 & 739.26 \\
\hline Lispro & $-0.08\left(-0.24 ; 0.08^{+}\right)$ & $0.67(0.61 ; 0.70)$ & $1,084.80$ & $1,191.50$ & $1,244.85$ \\
\hline \multicolumn{6}{|l|}{ Long acting } \\
\hline NPH & Reference & $0.34(0.32 ; 0.36)$ & 258.45 & 274.60 & 290.75 \\
\hline Glargine & $-0.04\left(-0.12 ; 0.05^{+}\right)$ & $0.33(0.30 ; 0.37)$ & $1,995.84$ & $2,195.42$ & $2,461.53$ \\
\hline Detemir & $-0.11\left(-0.32 ; 0.11^{+}\right)$ & $0.37(0.31 ; 0.44)$ & $1,448.86$ & $1,752.66$ & $2,056.45$ \\
\hline
\end{tabular}

${ }^{+}=$confidence interval shows that there is a possibility of increased HbA1c. Reference $=$the glycated reduction values were the benchmarks for insulin analogs. Costs were obtained according to the CMED Table 2016 and were calculated for the annual cost of treatment in accordance with the recommended regimen for each type of insulin. 
Fifteen scenarios were structured for the simulation of uncertainty in cost-effectiveness analysis. The mean, minimum, and maximum cost combinations, and largest and smallest cost difference with the mean, minimum and maximum effectiveness of each insulin showed that in face of the best-case scenario for the insulin analogs, i.e. least difference in cost and maximum effectiveness, the insulins aspart, lispro, glargine and detemir showed the ICER of $\mathrm{R} \$ 1,768.59 ; \mathrm{R} \$ 3,308.54 ; \mathrm{R} \$ 11,718.75$ and $\mathrm{R} \$ 2,685.22$, respectively. Additionally, in face of the worst-case scenario, i.e. largest cost difference and lowest effectiveness, all options were the dominated strategies, except aspart. The same was interpreted for all other scenarios in which minimal effectiveness was proposed (Table II).

Sensitivity analysis showed that in face of the probabilities of the effectiveness and cost variations, the insulin analogs aspart, lispro, glargine and detemir presented the ICER of R \$ 3,066.98; R \$ 5,960.39; R \$ $22,414.37$; and $\mathrm{R} \$ 6,163.97$, respectively. It is possible to highlight by sensitivity analysis that the option of the most cost effective fast acting insulin analog was aspart and long acting was detemir (Figure 1).

\section{DISCUSSION}

In direct cost analysis for the treatment of DM was possible to predict with $95 \%$ certainty that the minimum cost of insulin analog options was not less than the maximum cost of human insulin options, and the same evidence holds in the comparison between aspart and lispro. According to Holden et al. (2011), human insulins are preferred over insulin analogs in merit of cost savings to the government, given the expected effectiveness for the treatment of DM.

In all scenarios in which the lowest possible effectiveness is projected, the options lispro, glargine and detemir were dominated strategies and only aspart had ICER in trade-off, able to present an incremental cost for additional improvement in the outcome. When considering the mean effectiveness range, the most cost effective long-acting insulin option was detemir, R \$ 14,142.73 and, among the fast acting options the most cost effective was aspart, $R \$ 3,698.54$, being values added to the treatment for an additional reduction of $1 \%$ in HbAlc per patient/ year. In all scenarios, all options had an ICER less than the threshold of cost-effectiveness of R \$ 86,628.00 (amount equal to three times the per capita GDP of the year 2016). According to the opinion of the National Commission on Technology Incorporation in the BPHS (CONITEC, 2013), the ICER attributed to insulin analogs are not able to exceed the cost-effectiveness threshold.

Considering the best possible scenario for comparison of insulin analogs, among the fast-acting and long-acting insulins, aspart and detemir were the options that presented the best incremental cost effectiveness, being $\mathrm{R} \$ 1,768.59$ and $\mathrm{R} \$ 2,685.22$ per patient/year to reduce by an additional $1 \% \mathrm{HbA} 1 \mathrm{c}$ respectively. In the worst and best scenario, aspart and detemir insulin analogs had the lowest ICER compared with lispro and glargine. It is important that a $1 \%$ reduction in $\mathrm{HbA} 1 \mathrm{c}$ reduces by $43 \%$ the risk of amputation, in $14 \%$ the risk of acute myocardial infarction, and in $37 \%$ microvascular complications (SBD, 2016), so that the incremental cost represent the long-term economy of resources for the BPHS.

According to the sensitivity analysis by the decision

TABLE II - Incremental cost effectiveness in different scenarios for the simulation of the uncertainties in the comparison of insulin analogs with human insulin

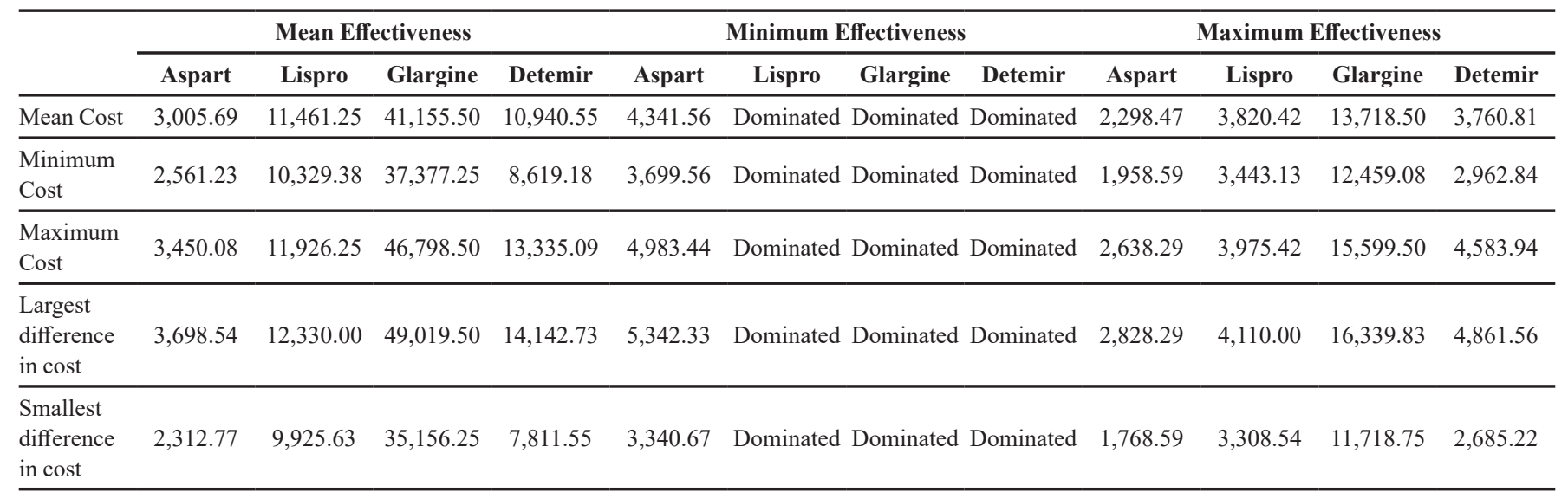

Largest difference $=$ difference between the lowest cost of human insulin and the highest cost of insulin analog. Smallest difference $=$ difference between the highest cost of human insulin and the lowest cost of insulin analog. Dominated = represents the strategy in which the insulin analog had a larger cost and a lower effectiveness when compared to human insulin. 

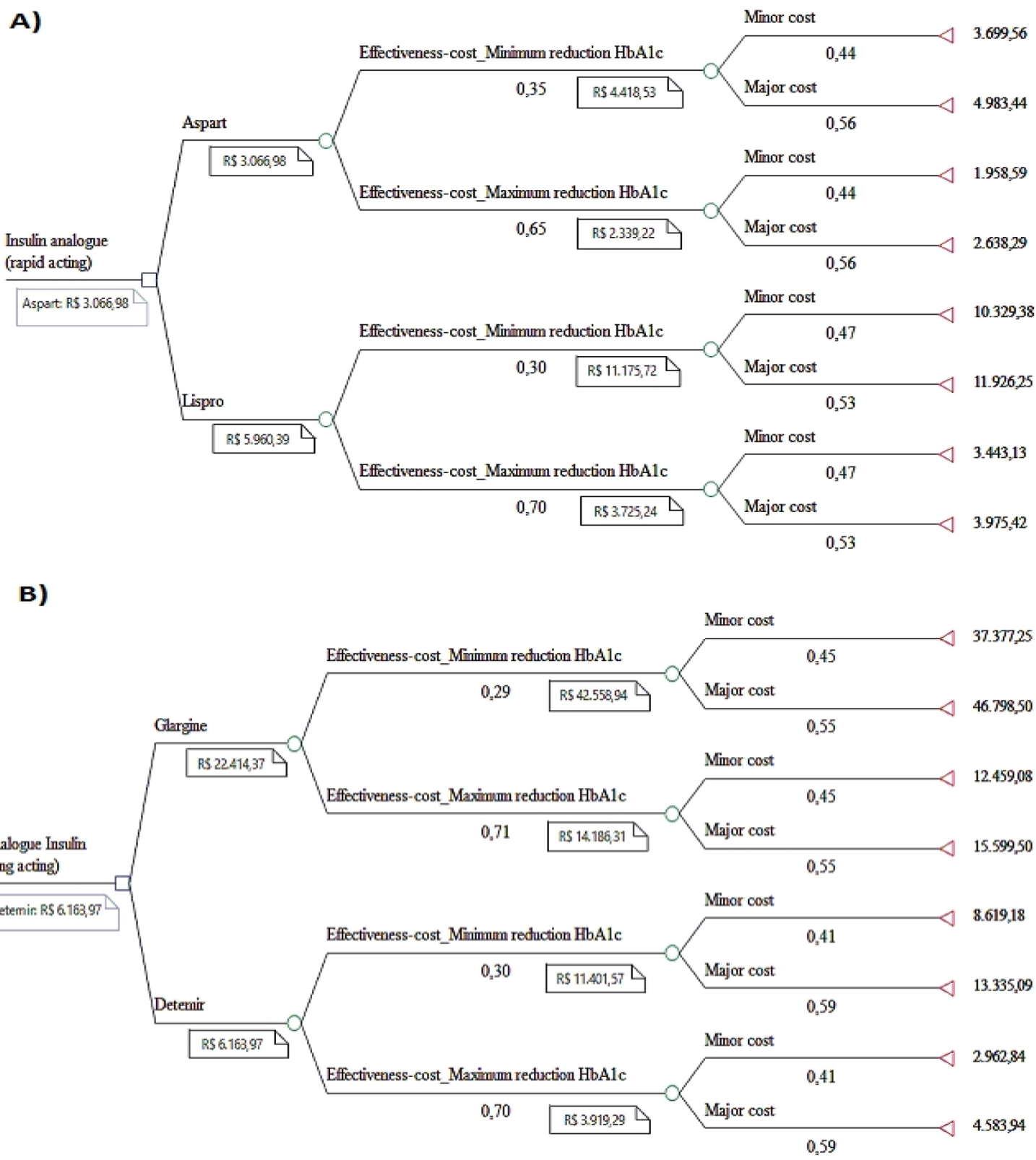

FIGURE 1 - Sensitivity analysis structured in a decision tree model for the Incremental Cost Effectiveness Ratio (ICER) of insulin analogs. A) structured sensitivity analysis for fast acting insulin analogs. B) Structured sensitivity analysis for long-acting insulin analogs. For the construction of the decision tree, the first node of the tree was considered as the decision node (square symbol) between the two types of insulin in each category, i.e. fast-acting and long-acting. The respective node of each insulin had a branch to two probability nodes (circle symbol), a node associated with the minimum and maximum effectiveness and another with the maximum and minimum cost. For the probabilities of each branch the $95 \%$ confidence interval was calculated, based on the range between the minimum and maximum reduction of glycated hemoglobin and minimum and maximum cost of insulin. The terminal node (triangle symbol) had values in Reais of incremental cost effectiveness for each possibility, taken from Table II. For the respective insulin of the dominated strategy when considering minimum effectiveness, the ICER was ranked from the scenario of minimum and maximum cost with the mean effectiveness of the insulins.

tree, the most cost effective fast-acting insulin analog was aspart, $\mathrm{R} \$ 3,066.98$ [95\% CI: 2339.22; 4418.53] and the most cost effective long-acting insulin was detemir, R\$ $6,163.97$ [95\% CI: 3919.29; 11401.57]. The result in face of the uncertainty simulation scenarios was maintained with sensitivity analysis, i.e., aspart and detemir were the most cost effective from the options. However, it was possible to identify increased ICER of aspart and 
detemir in accordance with the probabilities. This positive difference in the mean was $\mathrm{R} \$ 61.29$ and $\mathrm{R} \$ 4,776.58$, respectively. When comparing with the worst-case scenario, there was a negative difference of $\mathrm{R} \$ 631.56$ and $\mathrm{R} \$ 7,978.76$, respectively, and in the best scenario, a positive difference of $\mathrm{R} \$ 1,298.39$ and $\mathrm{R} \$ 3,478.75$ for aspart and detemir respectively.

It is important to stick to the scenarios of uncertainties, which showed that in the lowest-effectiveness hypothesis, the only option not dominated was aspart. This may be related to the effectiveness of lispro, which presented no evidence of better effectiveness compared with $\mathrm{R}$ insulin in clinical trials, unlike aspart which promoted significant improvement in glycemic control (Gale, 2000; Home, Lindholm, Riis, 2000). The same has been shown for longacting insulin analogs, which have not presented evidence of better efficacy when compared with NPH (Venancio et al., 2013).

The investment decision in aspart to improve glycemic control in diabetic patients can initially bring clinical benefits to patients and future financial benefits to the BPHS. However, this decision should have a plan, since budget impact studies indicate that the impact of the addition of insulin analogs into the BPHS can reach about 202.8 million Reais (CONITEC, 2013). In this way, the system cannot enjoy adequate capital for the initial investment which results in future financial benefits. Any poorly planned investment may compromise other sectors of health in Brazil.

One of the benefits highlighted for the use of insulin analogs over human insulin has been the significant reduction in the incidence of cases of hypoglycemia. Studies have shown that the improvement occurs in episodes of nocturnal hypoglycemia (Crasto et al., 2009; SDB, 2011; SDB, 2016). However, due to the data source used, this study did not consider episodes of diurnal, nocturnal and pre-prandial hypoglycemia, but instead, total hypoglycemic episodes. Thus, it is possible to emphasize that when evaluating the total episodes of hypoglycemia, the options of long and fast-acting insulin analogs poses no greater risks than NPH and Regular (Hermansen et al., 2001; CONITEC, 2013; Venancio et al., 2013).

According to the analysis by the values of Odds Ratio (OR) between the comparisons of total episodes of hypoglycemia, the meta-analysis used in this study has shown: detemir vs. $\mathrm{NPH}, \mathrm{OR}=0.88$ [0.52 to 1.51]; glargine vs. $\mathrm{NPH}, \mathrm{OR}=1.12$ [0.69 to 1.81 ]; lispro vs. insulin R, $\mathrm{OR}=0.72$ [0.21 to 2.55]; and aspart vs. insulin $\mathrm{R}, \mathrm{OR}=0.71$ [0.43 to 1.16]. These results mean that all insulins present the same risk to cause hypoglycemia (Sanches et al., 2013). It is noteworthy that the analysis performed in this study did not consider the cost of adverse reactions of the insulins.

It is relevant to point out that the assessment of cost-effectiveness of this study considered adult diabetic individuals, according to analysis performed by metaanalysis which provided the data for the study. We highlight there was no need to obtain other types of costs, such as indirect medical costs and non-medical costs since, given the perspective of this study (Rascati, 2010; CONITEC, 2013). Additionally, the effectiveness of each type of insulin was pertinent to insulin monotherapy, without adjuvant to DM treatment.

However, it is noteworthy that this study presents well-delineated results consistent with reality for Brazilian adult diabetic patients, and insulin without adjuvant treatment of DM. A relevant form of costing to the perspective of this study was used, in face of the BPHS and clinical data with high value of evidence (Savi, Silva, 2009). In addition, sensitivity analysis was performed based on a robust method for decision making, which uses statistical and mathematical tools that summarize in the decision tree model the best choice (Drummond et al., 2005; Rascati, 2010).

\section{CONCLUSION}

Assessing only the cost of treatment by direct cost analysis performed in this study, it was possible to conclude that Regular insulin and NPH were the best options for the treatment of DM. Still considering direct cost analysis, the insulins aspart and detemir were alternatives as the best choice among the insulin analog options, and aspart presented no possibilities of being more costly than the other fast-acting insulin options evaluated. According to sensitivity analysis, the best options among the insulin analogs were detemir and aspart. However, the insulin detemir was a dominated option according to uncertainty scenarios. Thus, our study showed there was evidence for aspart to be the most cost-effective insulin option when targeting an increment in reducing $\mathrm{HbA} 1 \mathrm{c}$ and possible improvement in glycemic control.

\section{ACKNOWLEDGEMENTS}

We thank Jonh Carpiter, from Ribeirão Preto-SP, for translation this manuscript. This work was supported by funding of São Paulo Research Foundation (FAPESP). This organization helped with scholarship for the author Maurilio Souza Cazarim [grant number 2014/020879], URL (http://bvs.fapesp.br/en/pesquisador/673633/ maurilio-de-souza-cazarim/). The funders had no role 
in study design, data collection and analysis, decision to publish, or preparation of the manuscript. Opinions, assumptions and conclusions or recommendations expressed in this article are responsibility of the authors and do not necessarily reflect the viewpoint of FAPESP.

\section{CONFLICT OF INTEREST}

The authors confirm that the content of this paper has no conflict of interest.

\section{REFERENCES}

American Diabetes Association. ADA. Standards of Medical Care in Diabetes - 2016. Diabetes Care. 2016;39(Suppl 1):S1112.

Anderson Jr JH, Brunelle RL, Koivisto VA, Pfützner A, Trautmann ME, Vignati L, et al. Reduction of Postprandial Hyperglycemia and Frequency of Hypoglicemia in IDDM Patients on Insulin-Analog Treatment. Diabetes. 1997;46(2):26570.

Agência Nacional de Vigilância Sanitária. ANVISA. Câmara de Regulação do Mercado de Medicamentos - CMED. Preços máximos de medicamentos por princípio ativo [Internet]. Brasília: ANVISA; 2016. [citado 2016 Jun 17]. Disponível em: http://portal.anvisa.gov.br/documents/374947/2829072/ LISTA+CONFORMIDADE_2016-06-17.pdf/d266d644-24524620-8ffc-2d77470023cd.

Brasil. Ministério da Saúde. Rede Brasileira de Avaliação de Tecnologia em Saúde (REBRATS). Diretrizes metodológicas: diretriz de avaliação econômica. 2.ed. Brasília: Ministério da Saúde; 2014. 131 p.

Brasil. Instituto Brasileiro de Geografia e Estatística. IBGE. Antropometria e estado nutricional de crianças, adolescentes e adultos no Brasil: Brasil: tabela 1.1. [citado 2016 Ago 17]. Disponível em: http://www.ibge.gov.br/home/ estatistica/populacao/condicaodevida/pof/2008_2009_encaa/ defaulttabzip_brasil.shtm.

Comissão Nacional de Incorporação de Tecnologias no SUS. CONITEC. Ministério da Saúde. Secretaria de Ciência, Tecnologia e Insumos Estratégicos. Departamento de Gestão e Incorporação de Tecnologias em Saúde. Insulinas análogas para Diabetes Mellitus tipo I. Relatório de Recomendação da Comissão Nacional de Incorporação de Tecnologias no SUS - CONITEC - 114. Brasília: Ministério da Saúde; 2013. 27 p.
Crasto W, Jarvis J, Khunti K, Davies MJ. New insulins and new insulin regimens: a review of their role in improving glycaemic control in patients with diabetes. Postgrad Med J. 2009;85(1003):257-67.

Do Livramento FA, Saleh SM. O fornecimento gratuito de medicamentos pelo Estado: um estudo do direito fundamental à saúde, pela análise da ação civil pública que pleiteia análogos de insulina x ações individuais. Amicus Curiae. 2011;7(7):1-17.

Drummond FM, Sculpher MJ, Torrance GW, O’Brien BJ, Stoddart GL. Methods for the economic evaluation of health care programmes. 3. ed. New York: Oxford University Press; 2005. $379 \mathrm{p}$.

Figueiredo TA, Osorio-de-Castro CGS, Pepe VLE. Evidencebased process for decision-making in the analysis of legal demands for medicines in Brazil. Cad Saude Publica. 2013;29(Suppl 1):S159-66.

Gale E. A randomized, controlled trial comparing insulin lispro with human soluble insulin in patients with Type 1 diabetes on intensified insulin therapy. The UK Trial Group. Diabetic Med. 2000;17(3):209-14.

Heller S, Koenen C, Bode B. Comparison of insulin detemir and insulin glargine in a basal-bolus regimen, with insulin aspart as the mealtime insulin, in patients with type 1 diabetes: a 52-week, multinational, randomized, openlabel, parallel-group, treat-totarget noninferiority trial. Clin Ther. 2009;31(10):2086-97.

Hermansen K, Madsbad S, Perrild H, Kristensen A, Axelsen $\mathrm{M}$. Comparison of the soluble basal insulin analog insulin detemir with NPH insulin: a randomized open crossover trial in type 1 diabetic subjects on basal-bolus therapy. Diabetes Care. 2001;24(2):296-301.

Hermansen K, Fontaine P, Kukolja KK, Peterkova V, Leth G, Gall MA. Insulin analogues (insulin detemir and insulin aspart) versus traditional human insulins (NPH insulin and regular human insulin) in basal-bolus therapy for patients with type 1 diabetes. Diabetologia. 2004;47(4):622-9.

Holden SE, Poole CD, Morgan CL, Currie CJ. Evaluation of the incremental cost to the National Health Service of prescribing analogue insulin. BMJ Open. 2011;1(2): e000258.

Home PD. Rapid-acting insulin analogues: when randomized clinical trial results do not help. Diabetic Med. 2000;17(Suppl 2):6-8. 
Home PD, Lindholm A, Riis A. Insulin aspart vs. human insulin in the management of long-term blood glucose control in Type 1 diabetes mellitus: A randomized controlled trial. Diabetic Med. 2000;17(11):762-70.

Lima J, Kolling AF, Nasser APP, Marques AF, Diquiqui R. Insulinas análogas: responsabilidade do SUS e a judicialização. Cad Ibero-Amer Dir Sanit. 2015;4(4):29-43.

Obreli-Neto PR, Marusic S, Guidoni CM, Baldoni AO, Renovato RD, Pilger D, et al. Economic evaluation of a pharmaceutical care program for elderly diabetic and hypertensive patients in primary health care: a 36-month randomized controlled clinical. J Manag Care Spec Pharm. 2015;21(1):66-75.

International Diabetes Federation. IDF. About diabetes. Diabetes: facts and figures. [cited 2016 Oct 31]. Available from: http://www.idf.org/about-diabetes/facts-figures.

Rascati KL. Introdução à Farmacoeconomia. 1. ed. Porto Alegre: Artmed; 2010. 280 p.

Sanches ACC, Correr CJ, Venson R, Gonçalves PR, Garcia MM, Piantavini MS, et al. Insulin analogues versus human insulin in type 1 diabetes: direct and indirect meta-analyses of efficacy and safety. Braz J Pharma Sci. 2013;49(3):501-9.

Savi MGM, da Silva EL. Information flow in the clinical practice of resident physicians: an analysis from an evidence-based medicine perspective. Ci Inf. 2009;38(3):177-91.
Shafie AA, Ng CH, Tan YP, Chaiyakunapruk N. Systematic review of the cost effectiveness of insulin analogues in Type 1 and Type 2 Diabetes Mellitus. PharmacoEconomics. 2016;34(2):1-22.

Sociedade Brasileira de Diabetes. SBD. Revisão sobre Análogos de Insulina: indicações e recomendações para a disponibilização pelos serviços públicos de saúde. São Paulo: SBD; 2011. 23 p.

Sociedade Brasileira de Diabetes. SBD. Diretrizes da Sociedade Brasileira de Diabetes (2015-2016). São Paulo: AC Farmacêutica; 2016. 337 p.

Venancio SI, Dallora MELV, Leichsenring ML, Nascimento ADF. Insulinas de ação prolongada no tratamento de diabete mellitus tipo 2. BIS. 2013;14(2):187-94.

Wagner EH, Sandhu N, Newton KM, Mcculloch DK, Ramsey $\mathrm{SD}$, Grothaus LC. Effect of improved glycemic control on health care costs and utilization. JAMA. 2001;285(2):182-9.

World Health Organization. WHO. Global Report on Diabetes. Geneva: WHO; 2016a. 86 p.

World Health Organization. WHO. Diabetes country profiles 2016. Brazil. [cited 2016b Oct 31]. Available from: http://www. who.int/diabetes/country-profiles/bra_en.pdf?ua $=1$.

Received for publication on $18^{\text {st }}$ November 2016 Accepted for publication on $01^{\text {st }}$ February 2017 